\title{
Telomestatin-induced stabilization of the human telomeric DNA quadruplex monitored by electrospray mass spectrometry
}

\author{
Frédéric Rosu, ${ }^{a}$ Valérie Gabelica, ${ }^{* a}$ Kazuo Shin-ya ${ }^{b}$ and Edwin De Pauw ${ }^{a}$ \\ ${ }^{a}$ Department of Chemistry, University of Liege, Sart-Tilman Bat. B6c, B-4000 Liège, Belgium. \\ Fax: (+32)-4-3663413; Tel: (+32)-4-3663432; E-mail: v.gabelica@ulg.ac.be \\ ${ }^{b}$ Institute of Molecular and Cellular Biosciences, The University of Tokyo, 1-1-1 Yayoi Bunkyo-ku, \\ Tokyo 113-0032, Japan.
}

This submission was created using the RSC ChemComm Template (DO NOT DELETE THIS TEXT) (LINE INCLUDED FOR SPACING ONLY - DO NOT DELETE THIS TEXT)

Electrospray mass spectrometry (ESI-MS) was used to monitor the kinetics of duplex formation between the human telomeric DNA quadruplex and its complementary strand. The complexation of telomestatin to the G-quadruplex delays the unwinding of the quadruplex structure and the formation of the duplex.

Chromosomal ends are protected from fusion events by telomeres, the end of which consisting in a 3' single strand overhang with the sequence repeat (GGGTTA) $)_{n}$. Telomere length is maintained by telomerase, a reverse transcriptase enzyme that is active in $85-90 \%$ of human tumors, but not in most normal somatic cells. Telomerase has therefore become an important target for anticancer drug design. ${ }^{1}$ An interesting approach for telomerase inhibition is to stabilize the telomeric Grich strand into a folded, inactive structure. The human telomeric strand $\left(\mathrm{G}_{3} \mathrm{~T}_{2} \mathrm{~A}\right)_{3} \mathrm{G}_{3}$ can fold into a G-quadruplex structure (Fig. $1 \mathrm{~A}$ and $1 \mathrm{C}$ ) that has been found to inhibit telomerase activity. ${ }^{2}$ The search for ligands that stabilize the folded G-quadruplex structure is of particular importance in telomerase inhibition strategies. $^{3 ; 4}$

The detection of drug-quadruplex complexes at equilibrium by ESI-MS has already been reported. ${ }^{5-8}$ Here we describe an electrospray mass spectrometric assay of the kinetics of hybridization of the human telomeric sequence, mimicking the binding to the RNA template of telomerase. The telomeric Grich strand (GGGTTA) ${ }_{3}$ GGG is mixed with its complementary strand (CCCAAT) ${ }_{3} \mathrm{CCC}$, which may adopt an i-motif conformation (Fig. 1C), and the formation of the complementary duplex is monitored as a function of time. The reaction kinetics is compared in the absence and in the presence of the quadruplex-binding drug telomestatin ${ }^{9}$ (Fig. 1B), which is a potent telomerase inhibitor. ${ }^{10}$

(A)
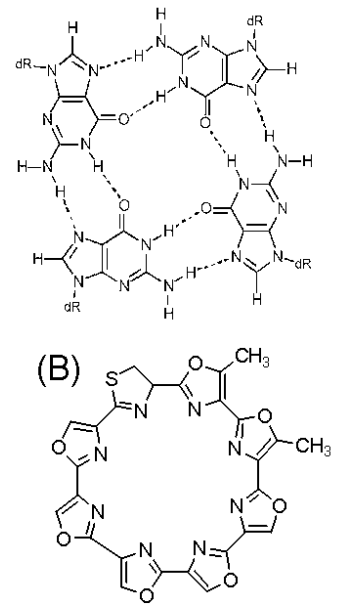

(C)

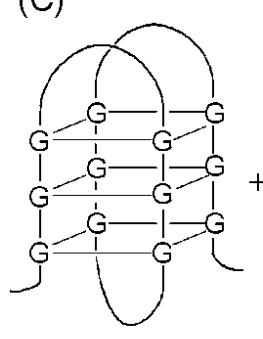

Quadruplex

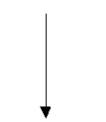

5'-GGGTTAGGGTTAGGGTTAGGG-3'

3'-CCCAATCCCAATCCCAATCCC-5'

Duplex
Fig. 1 (A) Structure of a guanine quartet. (B) Structure of telomestatin. (C) Design of the experiment: the G-quadruplex $\left(\mathrm{G}_{3} \mathrm{~T}_{2} \mathrm{~A}\right)_{3} \mathrm{G}_{3}$ is mixed with its complementary strand $\left(\mathrm{C}_{3} \mathrm{~A}_{2} \mathrm{~T}\right)_{3} \mathrm{C}_{3}$, adopting an i-motif structure. The hybridization of the two strands gives a Watson-Crick duplex.

Fig.2 (A) shows the ESI mass spectra of an equimolar mixture (5 $\mu \mathrm{M}+5 \mu \mathrm{M})$ of the telomeric sequence $\left(\mathrm{G}_{3} \mathrm{~T}_{2} \mathrm{~A}\right)_{3} \mathrm{G}_{3}$ and the complementary strand $\left(\mathrm{C}_{3} \mathrm{~A}_{2} \mathrm{~T}\right)_{3} \mathrm{C}_{3}$ at two different reaction times. $\dagger$ After $200 \mathrm{~s}$ (top) the mass spectrum shows peaks corresponding to the telomeric quadruplex (noted "G") at the charge state of 5- and 4- as previously described, ${ }^{6}$ and of the imotif $\left(\mathrm{C}_{3} \mathrm{~A}_{2} \mathrm{~T}\right)_{3} \mathrm{C}_{3}$ (noted "i") at $\mathrm{m} / \mathrm{z} 1239.2,1549.1$ and 2065.4 $\left([\mathrm{i}]^{5-},[\mathrm{i}]^{4-}\right.$ and $[\mathrm{i}]^{3-}$, respectively). The duplex formed by the strands $G$ and $i$ at $m / z 1835.3$ and 2141.2 (charge states 7- and 6) is already present. The intensities of the peaks of the C-rich strand are much higher than the G-rich one even at equimolar concentration, due to the higher hydrophobicity of the cytosine bases compared to the hydrophilic guanines. ${ }^{11}$ At $t=2000 \mathrm{~s}$, the duplex is the most abundant species. The relative intensities of free $\mathrm{G}$ and of the duplex are plotted as a function of time to determine the association kinetics (Fig. 3A). All charge states are summed up for the calculation of the intensities. The first $100 \mathrm{~s}$ are not accesible due to the time needed for mixing, injection, and obtaining a stable electrospray signal. The data were fit to a single exponential curve and the measured time constant $\tau$ of duplex formation is $532 \pm 11 \mathrm{~s}$.

Telomestatin is a drug that binds specifically to quadruplex DNA. ${ }^{5}$ The mass spectrum of an equimolar mixture $(5 \mu \mathrm{M}+5$ $\mu \mathrm{M})$ of quadruplex and telomestatin was recorded (data not shown). The equilibrium binding constants of the telomestatin:quadruplex complexes calculated using the method previously described ${ }^{12}$ are $K_{1}=1.2 \times 10^{5} \mathrm{M}^{-1}$ and $K_{2}=3.8 \times 10^{5}$ $\mathrm{M}^{-1}$. In our experimental conditions, $53 \%$ of the drug is bound to the quadruplex. The same order of magnitude for the two binding constants suggests that the binding sites are equivalent. Then $5 \mu \mathrm{M}$ of the complementary strand "i" was added to the (5 $\mu \mathrm{M}+5 \mu \mathrm{M})$ quadruplex:telomestatin mixture, and the reaction kinetics was followed as a function of time with ESI-MS. Fig. $2 \mathrm{~B}$ shows the ESI mass spectra obtained after $200 \mathrm{~s}$ (top) and $2000 \mathrm{~s}$ (bottom). No telomestatin complex could be observed either with $\left(\mathrm{C}_{3} \mathrm{~A}_{2} \mathrm{~T}\right)_{3} \mathrm{C}_{3}$ or with the duplex, confirming the high selectivity of telomestatin for the G-quadruplex structure. The relative abundances of the different forms of the G-strand (free G, 1:1 and 2:1 complex, and duplex) are plotted as a function of time in Figure 3B.

The relative intensity of the free G-quadruplex disappears with a time constant of $540 \pm 30 \mathrm{~s}$, which is the same as when no telomestatin drug is present, within experimental error. However the relative intensities of the $1: 1$ and 2:1 complexes do not decrease as fast as free $\mathrm{G}$, indicating that the displacement of the complexation equilibria is much slower than the hybridization of $\mathrm{G}$ with $\mathrm{i}$ to form the duplex. The relative intensity of 2:1 remains steady for $500 \mathrm{~ns}$, then it slowly converts into $1: 1$ by the loss of one drug. The relative intensity of the 1:1 complex starts to decrease on its turn after c.a. $1000 \mathrm{~s}$, to give free G-quadruplex which is believed to be immediately hybridized. The global time 

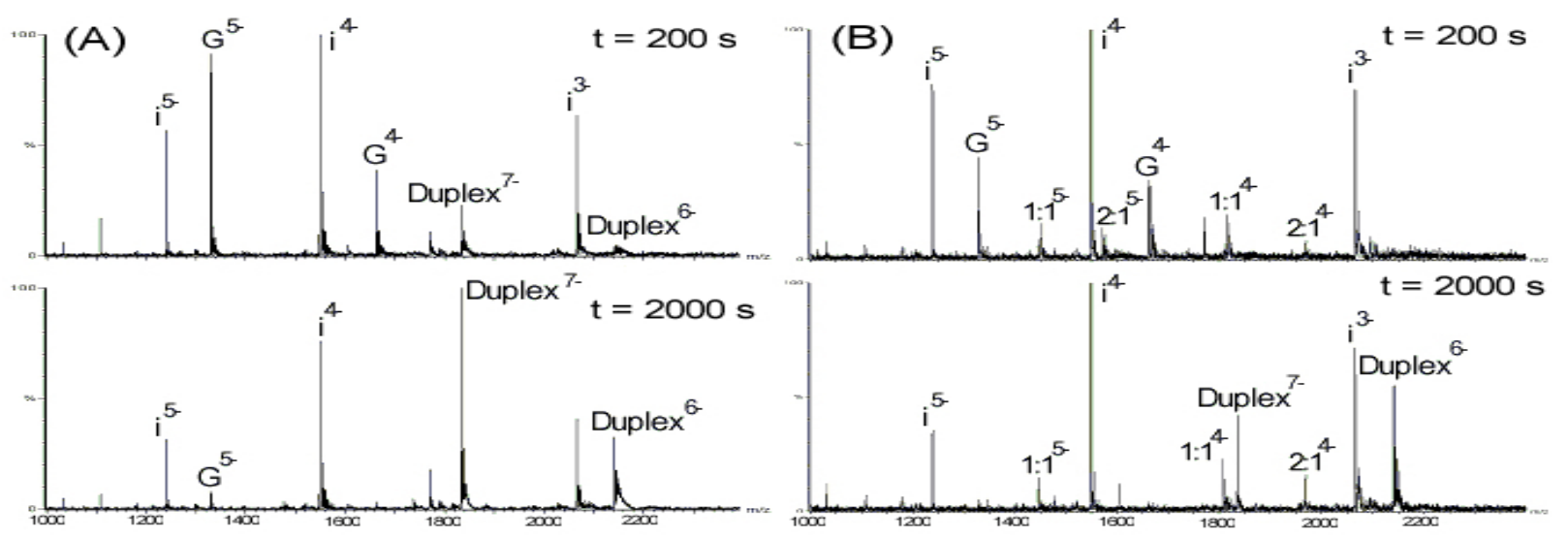

Fig. 2 (A) ESI-MS spectra of a mixture of $5 \mu \mathrm{M}$ (GGGTTA) ${ }_{3}$ GGG (“G”) and $5 \mu \mathrm{M}$ (CCCAAT) 3 CCC ("i") after $200 \mathrm{~s}$ (top) and $2000 \mathrm{~s}$ (bottom). (B) ESI-MS spectra of a mixture of $5 \mu \mathrm{M}$ "G", $5 \mu \mathrm{M}$ telomestatin, and $5 \mu \mathrm{M}$ "i" after $200 \mathrm{~s}$ (top) and $2000 \mathrm{~s}$ (bottom). "Duplex" stands for "G॰i"; "1:1" stands for "telomestatin॰G"; "2:1" stands for "2telomestatin•G".

constant for duplex formation ( $\tau=1010 \pm 90 \mathrm{~s}$ ) is increased twofold in the presence of telomestatin, due to the slow dissociation of the complex (Scheme 1).

$$
2: 1 \stackrel{\text { slow }}{\longleftarrow} 1: 1 \stackrel{\text { slow }}{\rightleftharpoons} \text { free } \mathrm{G} \stackrel{\text { fast }}{\longrightarrow} \text { duplex }
$$

Compared to other methods which allow the study of the kinetics quadruplex-to-duplex transition (circular dichroism, NMR, or fluorescence resonance energy transfer) ${ }^{13 ; 14}$, ESI-MS has the great advantage of monitoring each species individually, which is of prime importance for the study of the effect of drug binding on the reaction kinetics. The present study clearly shows that the selective complexation of telomestatin slows down the hybridization of the quadruplex. The rate-limiting step is the dissociation of the complexes with telomestatin. It therefore appears that drugs that bind selectively to quadruplex structures, and which are characterized by a high affinity constant and a low dissociation rate constant would effectively inhibit telomerase activity.

Fig. 3 Relative abundances of the different forms of the G-strand as a function of time. The complementary strand $(5 \mu \mathrm{M})$ is added to a solution $(5 \mu \mathrm{M})$ of preformed (GGGTTA) 3 GGG quadruplex (G) alone (A) or in the presence of $5 \mu \mathrm{M}$ Telomestatin (B). Black circles: duplex; white circles: free G-strand; grey triangles: 1:1 complex with telomestatin; grey hexagons: $2: 1$ complex with telomestatin.

\section{Notes and references}

$\dagger$ Single standed oligonucleotides were purchased from Eurogentec (Belgium). The quadruplex solution was prepared in $50 \mathrm{mM} \mathrm{NH} \mathrm{N}_{4} \mathrm{OAc}$, $\mathrm{pH}$ 6.5. The solution was heated to $80{ }^{\circ} \mathrm{C}$ for $5 \mathrm{~min}$ and the slowly cooled down to $20^{\circ} \mathrm{C}$ to form the quadruplex structure. These conditions are slightly different of our previously published protocol ${ }^{6,7}$ because we need to destabilize slightly the quadruplex structure to allow the online observation of the duplex formation in a reasonable time. The quadruplex melting temperature is reduced from $58{ }^{\circ} \mathrm{C}$ in $150 \mathrm{mM}$ $\mathrm{NH}_{4} \mathrm{OAc}^{7}$ to $39{ }^{\circ} \mathrm{C}$ in $50 \mathrm{mM} \mathrm{NH} \mathrm{H}_{4} \mathrm{OAc}$ (not shown). Experiments were performed on a Micromass Q-TOF Ultima Global apparatus operated in the negative ion mode. $15 \%$ methanol was added just before injection. The source parameters were the following: cone voltage: $35 \mathrm{~V}$, RF lens 1: $70 \mathrm{~V}$, source and desolvation temperatures: $70{ }^{\circ} \mathrm{C}$ and $100{ }^{\circ} \mathrm{C}$ respectively, collision energy: $10 \mathrm{eV}$.

1 L.H. Hurley, Nature Rev. Cancer, 2002, 2, 188-200.

2 A. M. Zahler, J. R. Williamson, T. R. Cech, D. M. Prescott, Nature, 1991, 350, 718-720.

3 J.-L. Mergny, C. Hélène, Nature Med., 1998, 4, 1366-1367.

4 H. Han, L.H. Hurley, Trends Pharm. Sci., 2000, 21, 136-142.

5 W.M. David, J. Brodbelt, S.M. Kerwin, P.W. Thomas, Anal. Chem., $2002,74,2029-2033$.
6 F. Rosu, V. Gabelica, C. Houssier, P. Colson, E. De Pauw, Rapid Commun. Mass Spectrom., 2002, 16, 1729-1736.

7 C. Carrasco, F. Rosu, V. Gabelica, C. Houssier, E. De Pauw, C. Garbay-Jaureguiberry, B. Roques, W.D. Wilson, J.B. Chaires, M.J. Waring, C. Bailly, ChemBioChem., 2002, 3, 100-106.

8 F. Rosu, E. De Pauw, L. Guittat, P. Alberti, L. Lacroix, P. Mailliet, J.-F. Riou, J.-L. Mergny, Biochemistry, 2003, 42, 10361.

9 K. Shin-ya, K. Wierzba, K. Matsuo, T. Ohtani, Y. Yamada, K. Furihata, Y. Hayakawa, H. Seto, J. Am. Chem. Soc., 2001, 123, $1262-1263$

10 M.-Y. Kim, H. Vankayalapati, K. Shin-ya, K. Wierzba, L. H. Hurley, J. Am. Chem. Soc., 2002, 124, 2098-2099.

11 A. P. Null, A. I. Nepomuceno, D. C. Muddiman, Anal. Chem., 2003, 75, 1331-1339.

12 F. Rosu, V. Gabelica, C. Houssier, E. De Pauw, Nucleic Acids Res., 2002, 30, e82.

13 W. Li, P. Wu, T. Ohmichi, N. Sugimoto, FEBS Lett., 2002, 526, $77-$ 81 .

14 A.-T. Phan and J.-L. Mergny, Nucleic Acids Res., 2002, 30, 4618 4625.
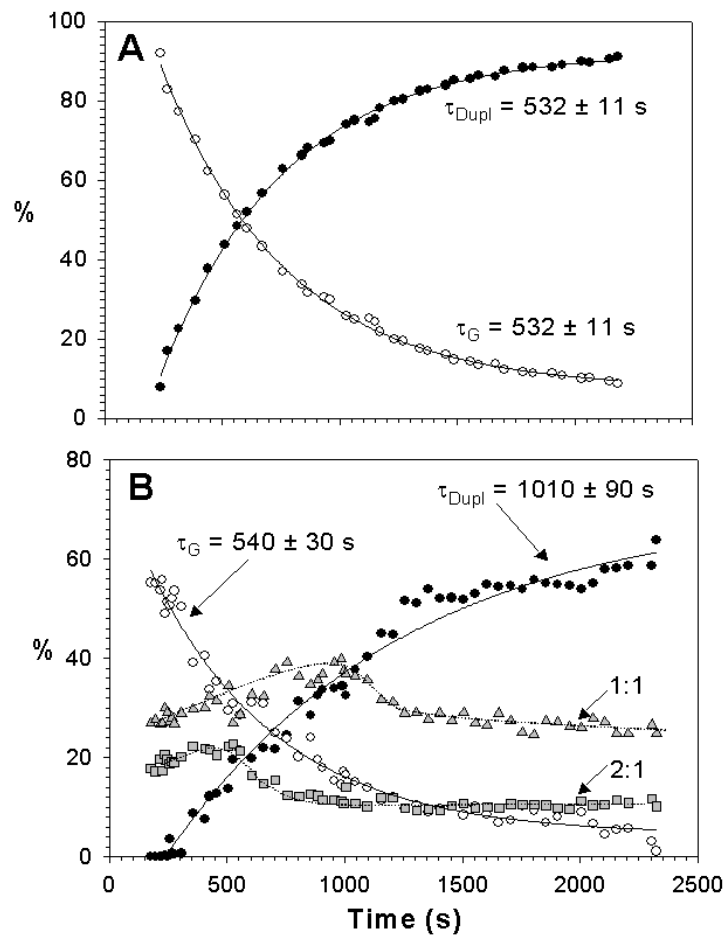
